\title{
Gratitude, Self-Interest, and Love
}

\author{
Y. Sandy Berkovski
}

Received: 6 November 2013 / Revised: 20 February 2014 / Accepted: 26 March 2014 /

Published online: 7 May 2014

(C) Springer Science+Business Media Dordrecht 2014

\begin{abstract}
Gratitude is usually conceived as a uniquely appropriate response to goodwill. A grateful person is bound to reward an act of goodwill in some appropriately proportionate way. I argue that goodwill, when interpreted as love, should require no reward. Consequently, the idea of gratitude as a proportionate response to love is not intelligible. However, goodwill can also be understood merely as a disinterested concern. Such forms of goodwill are involved in reciprocal relationships. But gratitude has no place in these relationships either.
\end{abstract}

Keywords Gratitude $\cdot$ Benevolence $\cdot$ Love $\cdot$ Self interest

\section{Introduction}

The term 'gratitude' is ambiguous. You helped me in fixing my car, and now I have a certain psychological experience that I describe as a 'feeling of gratitude'. Motivated by this feeling, I decide to buy you a box of chocolates. This act I describe as an 'act of gratitude'. Or I could say that buying the chocolates was a 'sign of gratitude': it was an expression of a grateful feeling that I have for you. In the vernacular 'gratitude' can refer to a feeling, as well as to its outward manifestation, an act. In moral philosophy, however, most attention has been devoted to the examination of the duty of gratitude. A philosophical theory of gratitude has, therefore, two objectives. One is to explicate the duty of gratitude. The standard procedure here is to look at the circumstances where the duty is supposed to arise, and to ask in what way one must discharge the duty. Another objective is to show the significance of gratitude in our moral behaviour. The focus of this paper is by and large on the first objective. I will

Y. S. Berkovski $(\bowtie)$

Department of Philosophy, Bilkent University, Ankara 06800, Turkey

e-mail: sandy.berkovski@gmail.com 
argue that in the situations where the duty of gratitude is supposed to arise it is in fact unintelligible. Consequently, as an independent normative factor of behaviour, gratitude is non-existent. ${ }^{1}$

\section{What the Duty of Gratitude is not}

To isolate the occasions where the putative duty of gratitude should arise, let me begin by looking at the occasions where, according to most theorists, it does not arise. On these occasions there is evidence, though possibly not conclusive, for the occurrence of gratitude - in some sense of 'gratitude'. But there are also good reasons for thinking that the unique duty of gratitude is absent there. Some such occasions belong to the context of feeling. Walter Scott writes in his diary:

I made not the slightest pause, nor dreamed a single dream, nor even changed my side. This is a blessing to be grateful for. (3 February 1826)

A certain feeling may plausibly be ascribed to the diarist. It does not have to be specifically a religious feeling: conceivably, Scott is not grateful to anyone in particular, God included, when he is writing these lines. He is not expected to manifest his gratitude in any specific way, such as prayer or sacrifice. The same feeling may be in play when there is an addressee ('I am grateful to Aulus Gellius for preserving the opinions of classical writers'). Perhaps, as some psychologists and philosophers assure us, the agent's contentment is more secure with the feeling of gratitude. Perhaps the propensity for having this emotion makes a person a more valuable moral agent. It may improve his character by, for example, aiding him in overcoming his fits of anger. ${ }^{2}$ But, as far as the system of obligations is concerned, his feeling is inconsequential. Later in section "Feelings, Reciprocity, and Helping Strangers", however, doubts will emerge about the blank characterisation of such feelings as 'gratitude'.

On other occasions, gratitude expressions occur in the context of etiquette. Thus, in Anglo-Saxon countries especially, bus drivers are thanked at the completion of one's journey, salespersons routinely thank customers at the completion of purchase transactions, and generally any offer, however inconsequential, is reciprocated with words of thankfulness. Conveying gratitude, by uttering those words of thankfulness, in the context of etiquette does not represent a distinctive obligation. A person who fails to say thanks to the bus driver would possibly be considered a rude person. But he would not be judged morally ungrateful. And this is not surprising. One of etiquette's features is that words in its context often do not have their literal meaning. When a colleague signs her letter to you 'Yours ever', the expression implies neither that she is yours always, nor even that she is yours sometimes. Its presence on the page is supposed to convey her commitment to the standards of polite conversation.

\footnotetext{
${ }^{1}$ A note on terminology: as all other writers writing on this topic, I am using the terms 'duty' and 'obligation' interchangeably. For a distinction between the terms see Simmons (1979, 167-168) and also Gilbert (2006, 35-36).

${ }^{2}$ See Fitzgerald (1998) and Buck (2004) for an extensive treatment of gratitude in the context of feeling. Gratitude as a feeling was earlier discussed in Walker (1980) under the rubric of 'gratefulness'.
} 
Possibly also, it indicates the colleague's enduring minimal respect for you: you are taken as a worthy player, to at least a minimal extent, in a social interaction. So in general, the words of thankfulness occurring in the context of etiquette may convey ethically relevant content, but one that has nothing to do with gratitude properly so called. Thus, within that context, not only is there (normally) no place for a grateful feeling, there is also no genuine act of gratitude. The participants in the interaction signal to each other their status as candidates for civil communication. The same status, in other countries or other ages, can be obtained by other means circumventing the expressions of gratitude altogether. ${ }^{3}$

A rather parochial context of etiquette is to be distinguished from a universally recognised context of market. In this context the parties-the benefactor and the beneficiary - might not be in any antecedent market (business) relationship. A market framework is created at the time of one party's granting a favour - or perhaps earlier if the favour was requested - and the other party's acceptance of it. The putative benefactor acts in the expectation of a reward: the reward provides him with a reason for his action. It is also granted that the beneficiary, through his knowledge of the given context, is aware of this fact. When the reward is not forthcoming, the benefactor considers himself cheated. The obligation of market gratitude is genuine, but it is no different from a general obligation of obeying the terms of contract. To fail in the obligation of market gratitude is to cheat and to act unfairly to the benefactor. 4

If there is to be any special character to this form of gratitude, it is in the nature of a reward associated with it. Sometimes we act for the sake of appreciation coming from other people, rather than for any material reward. Obligations of market gratitude fit these occasions. They go beyond achieving beneficial material results and reach to the agent's attitudes in rewarding the benefactor. A thankyou statement qualifies as a reward, at least in part, because of the attitude it is presumed to indicate. That people desire to be loved is a plain element of human psychology whose anthropological or ethical causes need not detain us at the moment. One aspect of love (to be elaborated below) is the perception of uniqueness created in the beloved. I want to be loved for what uniquely I am, and not simply because I happen to instantiate a certain quality or relation. Contracts, especially when they are formalised and put on paper, are peculiarly not suitable for conveying love. One immediate reason is that a mental attitude cannot become part of a contract. At most its outward signs could. But secondly, contracts specify general conditions under which a business deal goes forward. Far from being acknowledged for his uniqueness, the putative benefactor would be rewarded merely as someone with such and such qualities. The role of market

\footnotetext{
${ }^{3}$ The social role of politeness has been explored in linguistics. For useful review articles see Kasper (1990) and Bargiela-Chiappini (2003). Two illuminating discussions of the moral significance of etiquette are in Cicero's On Duties (the doctrine of decorum in Book I) and in Elias (1982).

${ }^{4}$ The context of etiquette may be seen as a special case of the context of market when the rules of etiquette constitute the reward expected by one of the parties. When I check into a Waldorf-Astoria, I may expect a certain level of politeness and etiquette to be part of my bargain with the hotel. Nevertheless it appears clear that on many occasions where a code of etiquette is required-on the street, in a local shop-it is best understood as an integral part of civil communication, rather than that of a business dealing.
} 
gratitude is to avoid both pitfalls. Therefore, it arises in those cases where the reward is love, praise, and appreciation, possibly in addition to a tangible reward. ${ }^{5}$

\section{What the Duty of Gratitude is}

To introduce the context where the duty of gratitude is indeed supposed to arise, let me begin by distinguishing between two kinds of benefactors. (1) $X$ is a g-benefactor of $Y$ if and only if $X$ performed an action whose goal was to benefit (to serve the interest of) $Y$ and that goal was achieved. ${ }^{6}$ In much of the common usage the term 'benefactor' corresponds to ' $\mathrm{g}$-benefactor'. It is normal to call a 'benefactor' someone who provided benefits, ignoring altogether the content of his motivation. (2) A stronger clause obtains once we examine the agent's motivation: $X$ is an m-benefactor of $Y$ if and only if $X$ performed an action whose goal and motive were both to benefit (to serve the interest of) $Y$ and that goal was achieved. Since, I take it, actions are characterised by their goals, the agent may perform the same kind of action with different motives. The action of donation to a charity has its goal the donation to that charity. But it can be done with a motive of duty or with a motive of getting tax breaks, among other possible motives. On two different occasions we may have the same action-type motivated by different considerations.

In addition to 'g-benefactors' and 'm-benefactors' we can also talk of 'g-beneficent' and 'm-beneficent' actions, or generally of 'g-beneficence' and 'm-beneficence'. G-beneficence sometimes occurs in the context of market. If it is known that a person routinely donating money to a charity takes particular pleasure in getting mentioned in its annual report, then in effect a tacit conditional offer was made by the g-benefactor. The tacit condition stipulated a certain demand from the beneficiary. Then, for the beneficiary, it would be right and fair to mention the benefactor's name in the report with the appropriate expression of thanks. That expression - a reward coming in the form of honour-would be an expression of market gratitude. Expressions of gratitude, on such occasions, are just one kind of the conditions the g-benefactor might have stipulated. An m-benefactor, by contrast, attaches no demands to his offer. Despite that, it seems that the beneficiary owes a particular, special 'debt of gratitude' to the benefactor. Such a response would be a uniquely appropriate response, not to the benefit itself, but to the m-benefactor's motive manifested in his action.

\footnotetext{
${ }^{5}$ That expressions of gratitude in the context of market are not part of the 'real' duty of gratitude is emphasised in Simmons (1979).

${ }^{6}$ What if the goal was not achieved? Suppose you respond to my request to loan me a sum of money, but the money is stolen before I actually receive it. Am I to remain entirely indifferent to you simply because of that bad luck? Certainly not. You tried to benefit me, you acted on your desire to help, and you have achieved something — namely, moved the money and actually made an effort. So I should be grateful for that effort. Though the greater overall action of loaning the money did not achieve its goal, there were lesser intermediate actions that did. For instance, you went to the bank, you liquidated your stocks to send me cash, you cut on your own expenses. All these successfully completed actions make you a g-benefactor. Still, it seems to me that the reward to the benefactor should be less in such a case than it would have been had the money not been lost.
} 
This indeed is the concept of gratitude prevalent in the majority of ancient and modern theories. Here is a sample of prominent discussions:

What, then, is a favour [meriting a grateful response]? An act of benevolence bestowing joy and deriving joy from bestowing it, with an inclination and spontaneous readiness to do so. (Seneca, On Favours I 6.1) ${ }^{7}$

Benevolence is satisfaction in the happiness (well-being) of others; but beneficence is the maxim of making others' happiness one's end [...]. To be beneficent, that is, to promote according to one's means the happiness of others in need, without hoping for something in return, is every man's duty. [...] Gratitude consists in honoring a person because of a benefit he has rendered us. The feeling connected with this judgment is respect for the benefactor (who puts one under obligation), whereas the benefactor is viewed as only in a relation of love toward the recipient. (Kant, The Metaphysics of Morals, 452-454) ${ }^{8}$

[The] principle, underlying cooperation, differs from gratitude in a crucial respect. Cooperation does not imply benevolence; it is compatible with complete, but enlightened, self-interest. Selfish motivation on the part of the participants in no way diminishes the obligation to reciprocate with the requisite behavior when one has enjoyed the benefits of the practice. The point of such an activity is to produce mutual benefits. (Berger 1975, 301)

[T] he benefactor must not have provided the benefit for reasons of selfinterest. While again we may be "grateful that" the benefits were provided for us, the benefactor is owed no debt of gratitude if those benefits were provided for the wrong reasons. [...] This discussion will help us to see the contrast between a principle of gratitude and [...] the principle of fair play. Under the principle of fair play, an individual's sacrifices within a cooperative scheme may create for others an obligation to repay him, even if the individual's reasons for making the sacrifices were purely self-interested [...]. (Simmons 1979, 171-172)

Acts of gratitude, then, properly so called, take place in the contexts of goodwill where the benevolent benefactor (m-benefactor) displays his goodwill towards another person. Only in these contexts there should arise underivative sui generis obligations of what one may call, for a lack of a better term, 'sui generis gratitude'. It can no longer be justified by an appeal to the market relation and fair play: to do that would be to ascribe to the benefactor the pursuit of self-interest. In violating the terms of the agreement, the ungrateful beneficiary would harm the benefactor-that is, damage his self-interest grounding the agreement. But in the context of goodwill the benefactor is supposed to have renounced the pursuit of self-interest and to have

\footnotetext{
${ }^{7}$ Seneca translations are from the Seneca (1995) edition.

${ }^{8}$ Kant translations are from the Kant (1991) edition (pagination follows the Prussian Academy edition). An egoistic g-benefactor may still be honoured for the benefits provided. Thus, in general, such honour could not count as a unique response to the m-beneficence Kant describes before this sentence. It should also be noted that, while emphasising the 'sacredness' of (sui generis) gratitude, Kant completely ignores our problem of its justification. See Smit and Timmons (2011).
} 
provided his gift outside the framework of any fair-play agreement (but see below for a qualification of this claim).

For this reason obligations of sui generis gratitude are to be discharged in a unique and rather complex way. Repaying the m-benefactor should neither be interpreted, nor meant to be interpreted, as satisfying the benefactor's self-interest. On the contrary: the beneficiary should ensure an effective communication of his acknowledgement of the benefactor's disinterested intent-namely, his goodwill. Thus a neighbour, in offering to babysit Rowena's daughter, is sensibly interpreted as pursuing no personal gain from that offer. Since the offer would be a sign of goodwill towards her, the reward that Rowena should reciprocate him with is not a form of compensation. It should rather be thought as a sign of acknowledging and appreciating his goodwill.

Along with the contrasts, it is essential to note the similarities between sui generis gratitude and market gratitude. Both in the context of market and in the context of goodwill, the beneficiary, and he alone, 'owes a debt' to the benefactor. The failure to repay the debt implies the failure to discharge the duty of sui generis gratitude. Other agents can form positive attitudes towards the benefactor, but none of them has to reciprocate him for his beneficial action. In discharging the duty of gratitude we track the past behaviour of the benefactor and reward him with a good that is proportionate in value to his original benefit. As the theorists of gratitude have long realised, we do not have to reciprocate the material benefit we have received with a benefit comparable in its material value. ${ }^{9}$ This, as we have seen, is true even of the market gratitude where a reward may come simply in the form of praise. But there a reward was expected and demanded. In the context of goodwill, on the other hand, reciprocation is supposed to be particularly delicate: the beneficiary must take special care not to misrepresent the benefactor's intent. He must not, that is, in rewarding the benefactor ascribe to him a pursuit of self-interest. He must not imply by his action that its goal is in fulfilling the demands and expectations of the benefactor.

\section{Two Questions About Benevolence}

There are two complications we have to address right away. One is the very existence of m-benefactors. Any account of sui generis gratitude should rest on the assumption of the m-benefactor's initial goodwill. Without this assumption there is no actual situation demanding the performance of the duty of sui generis gratitude. This in effect is the view taken in Hobbes' Leviathan. ${ }^{10}$ In a characteristically concise and clear discussion, gratitude is declared by Hobbes to be a 'law of nature', i.e. a rational principle guiding man's behaviour. It is nothing else but a form of justice, whereas justice is by definition a form of a contractual relationship. Men, in their voluntary

\footnotetext{
${ }^{9}$ E.g. Seneca in On Favours I.6, II 31.2 and most recently von Tevenar (2006).

${ }^{10}$ See Leviathan XV and also De Cive III.7. In recent literature Card (1988) develops a revisionist account of gratitude whose starting point is Hobbes's view. See also footnote 27 below.
} 
actions, invariably pursue their own self-interest (their 'own Good', as Hobbes puts it). So even gifts that might appear free are not really so: in making them the giver expects a reward. The receiver is presumed to understand this conative mechanism guiding the giver by the same process of reasoning that urges him to seek peace and obey the terms of usual contracts. ${ }^{11}$ Frustrating the giver's expectations is no different from frustrating the expectations of the other side in usual contracts, and is thus contrary to justice.

In other words, for Hobbes, the duty of gratitude is only discharged in the context of market. The context of goodwill is rendered impossible (among actual humans), since it presupposes motives and intentions other than the promotion of the agent's own interest. Every act of putative benevolence in fact sets up an implicit agreement. Such an agreement then creates an obligation entirely within the scope of contractual fairness.

This is obviously not the place to debate Hobbes' moral psychology. At all events, my purpose here is to examine the phenomenon of gratitude given the possibility of benevolence. And this possibility is a default assumption in our assessment of human action. This is a matter of course in our personal relations with close friends and loved ones. But the same assumption is made even when we interact with people acting in their official capacities defined by the market. A fireman who saves a person from a burning house, a bank teller reinstating to the customer a thousand pounds the latter has mistakenly deposited, even a tour guide providing an exceptionally competent lecture at an art gallery-their actions are apt to generate that feeling of gratitude which separates the context of goodwill from the context of market. That is how, as a matter of fact, we construe a moral approach to these circumstances. Even after we are told that the putative benefactors were only 'doing their jobs', we still retain a distinctive feeling for them. Having that feeling, we are apt to develop a certain special attitude towards them. And if anyone were to fail to develop such an attitude, we would reproach him for a lack of an appropriate moral quality.

This attitude is not inexplicable. In observing the fireman's action we realise that the fireman could not just be doing his job. There is more than one way of doing one's job properly. If the fireman were motivated exclusively by the desire to do his job, in all likelihood he would not have risked his life. The fireman on that occasion, the assumption goes, was motivated only in part by the desire to do his job properly. He was also motivated by the feeling of sympathy. The fireman, in insisting he was only doing his job, displays commendable modesty, but misdescribes his own action. His motivation was a mixture, whose exact proportions are undetermined, of benevolence and fulfilling the terms of his employment contract. Sui generis gratitude is due in recognition of his benevolent intent.

This brings us to the second complication. The duty of sui generis gratitude, I said, is the duty of an appropriate response to the m-benefactor's motive

\footnotetext{
${ }^{11}$ Some care should be exercised here. The obligation of gratitude, according to Hobbes, arises also in the situations where contracts cannot be legally binding. Thus a sovereign must be grateful to his subjects, but not at all because there is a legal obligation on him to be so. This complication should not, I think, undermine the contractual nature of gratitude. (Thanks to Lars Vinx for pressing this point.)
} 
in benefiting the favour's recipient. ${ }^{12}$ But what should the exact place of benevolence in the m-benefactor's motivation be for it to ensure the necessity of a grateful response? Clearly $(a)$ if benevolence were the only motive of the action, a grateful response should be in order. Most of the time, though, the motivational content is fairly mixed: people often act from a plurality of motives. Now, it seems equally clear to $(b)$ me that if benevolence were the only sufficient motive, a grateful response is also necessitated, $(c)$ and that if benevolence were not among its jointly sufficient motives, a grateful response is not necessitated. ${ }^{13}$ At all events, I will not spend time defending these claims. What, I think, remains to be seen is $(d)$ whether gratitude is in order where a benevolent motive is merely one of jointly sufficient motives (i.e. where benevolence is a member of the smallest set of jointly sufficient motives of the given action).

One problem with the latter kind of situation is that self-interest may be another member in the set of jointly sufficient motives. Then the benefactor may be said to have provided a benefit 'out of self-interest' in which case sui generis gratitude would seem out of place (see the quotations above). If we are prepared to allow a clean separation between motives, the problem can easily be resolved. Suppose that three rings got lost, and that Wilfred has recovered all three of them. Further circumstances are as follows. Ring $X$ : [A wedding ring belonging to a young bride who regrets its loss deeply. No reward promised for its return.] Ring $Y$ : [Belongs to a wealthy woman who has no special use for it. A hefty reward is announced by her secretary as a matter of general policy.] Ring Z: [A wedding ring belonging to a young bride who regrets its loss deeply. A hefty reward promised for its return.]. Suppose that Wilfred is fully aware of these facts, and that he can only return one ring to its owner. Upon a brief reflection, he decides to return $Z$. Conceivably this shows, when we take his other options into account, that he was governed by two jointly sufficient motives: the desire for a reward and the desire to help the owner of $Z$. Wilfred's action took place in a mixed context of market and sui generis gratitude.

The owner of $Z$, if she has a perfect insight into Wildred's motivation, would be placed under two obligations: the obligation to pay the reward and the obligation of sui generis gratitude whose debt will be discharged in the future. The grateful response should come in acknowledgement of Wilfred's benevolent motive. In real life scenarios things are far more obscure. The problem is not only that no one, not even the agent himself, has a perfect view of the ingredients of his motivation. Generally, I think, we also have a difficulty with understanding how different motives can be mixed in equal proportions, or even how one motive can be 'more' dominant than another. We do not know exactly what it means, and we do not know how to react to them. Despite the frequent lip service paid to the complexity of motives, we tend to simplify. It is more convenient to select one motive and make it the only sufficient one, so that we could neatly attach the labels of 'selfish', 'generous', or 'moral'

\footnotetext{
${ }^{12}$ The ensuing discussion is heavily influenced by Herman (1993).

${ }^{13}$ There are reasons to think that in this scenario benevolence would not be a motive at all. See Herman (1993, 11-13) and references therein.
} 
actions. With these provisos, I will assume that benevolence should at least be one of jointly sufficient motives for the action to merit a sui generis grateful response.

\section{The Goodwill in the Context of Goodwill}

According to the line of thought explored in section "What the Duty of Gratitude is"section "Two Questions About Benevolence", gratitude is possible so far as goodwill is possible, and goodwill is possible as a brute fact of human nature. Acts of gratitude are the uniquely appropriate reaction to goodwill. Gratitude signifies appreciation of the ingredient of goodwill contained in the motivational mixture of the given action. But if this were all there is in gratitude, we could not distinguish it from another appropriate reaction to goodwill-namely, approval. Observing an act of benevolence should generate an attitude of approval, possibly followed by some form of material manifestation. Approval can be a reaction to just about any action, including an act of goodwill performed towards myself or someone else completely unrelated to me. Gratitude is an egocentric reaction to an act of an m-benefactor: it is a reaction to an act of goodwill performed specifically toward $m e{ }^{14}$ The motives driving the m-benefactor do not have to contravene a moral principle; still, if the action is done solely on such a principle, it is not clear whether gratitude is due. Any moral action must possess a degree of impartiality. But if ethical calculations yielded the result that I am to be granted that benefit, and if the attitude of the benefactor merely followed those calculations, my well-being is incidental to the action. An impartial action whose purpose is to satisfy a moral rule should elicit from me a reaction no different from the reaction of some observer in the vicinity. And the praise the benefactor may receive for adopting an ethical course of action is again not sufficient for differentiating my reaction from the reaction of a morally good observer. In other words, to think of goodwill meriting gratitude as morally informed is to assimilate the reaction of gratitude to the reaction of approval, and so to discard the concept of sui generis gratitude. ${ }^{15}$

That goodwill in the context of goodwill does not necessarily have a moral character is, I think, relatively obvious. Think of the earlier example of the lost rings. It is not clear at all what morally right course of action should be suggested for Wilfred. It is especially unclear whether there is a way to decide between returning the ring $X$ and the ring $Z$. Perhaps the right way out would be tossing a coin. On the other hand, if Wilfred decides to return $Z$ simply because he prefers to benefit the owner of $Z$, rather than the owner of $X$, this action should rightly elicit a grateful response on behalf of its owner.

It may be objected that an obviously immoral action cannot merit a grateful response. If Wilfred steals a ring in order to give it to Rebecca as a gift, the latter ought not to be grateful for it. Therefore, the gratitude-inducing goodwill should at

\footnotetext{
${ }^{14}$ As recognised already by Seneca in On Favours I.14.

${ }^{15}$ For the doubts that duty-motivated actions merit gratitude see Simmons (1979, 181-82).
} 
least be in accordance with the moral course of action. This conclusion is premature. Rebecca, for example, can sensibly be interpreted as not wanting to possess a stolen good in the first place. Since Wilfred would then be forcing the ring upon the beneficiary against her wishes, the beneficiary (Rebecca) is under no obligation of gratitude. In other cases, the beneficiary may be grateful, but whatever duty of gratitude he has would be overshadowed by the duty to condemn an immoral act. Suppose Rebecca has a rare disease that can only be healed by an ancient ring kept in the British Museum. She explicitly asks Wilfred to get her that ring, by stealing if necessary. And suppose that Wilfred has successfully got the ring after putting himself through considerable risk. Unfortunately, in the course of his heist he had to shoot dead several guards. Now, it seems to me that, on the standard account, Rebecca might still be under an obligation of gratitude, so far as Wilfred was driven by the concern for her well-being. But that at the same time she would also be under an obligation to show her strong moral disapproval. The latter obligation would dominate and obscure whatever duty of gratitude she is under.

With the moral connotation out of the way, how should we explicate the goodwill meriting a grateful response? The goodwill of an m-benefactor, we have now found, is opposed to self-interest. It is a demonstration of partiality, and it is reflected in a concern for the beneficiary. Love, in its pre-theoretic sense at least, seems to share all of these characteristics. So perhaps the goodwill of an m-benefactor is nothing but love. A benevolent action meriting a sui generis grateful response is a manifestation of love the benefactor has for the beneficiary. Sui generis gratitude, its obligation, is a response to an expression of a love emotion. This is not an implausible assumption at least in the cases where we benefit our parents, children, close friends, or our partners. On such occasions our actions may be said to be motivated by love. The characteristics of partiality and disinterested concern mentioned earlier would then be attributed to the benefactor's motivation. So in these cases the problem before us is whether love can necessitate the duty of a grateful response, and whether we could still distinguish that response from mere approval.

\section{A Strange Case of Double Vision}

The difficulty with defending an obligation of a grateful response to a loving act is perhaps most straightforward if we endorse irrationalism about love. On this view defended by Harry Frankfurt, love does not arise, and is not maintained, for any reasons. ${ }^{16}$ Love is itself the source of reasons for acting toward the beloved. It is the source of valuing of the beloved. Whereas certain qualities of the beloved may play a causal role in generating love, those very qualities might be seen by the lover as not especially valuable or even as outright bad. Love simply happens to the lover, despite him having no good reasons to have it. We say that the lover 'cannot help' but love his beloved. ${ }^{17}$

\footnotetext{
${ }^{16}$ See Frankfurt (2004).

${ }^{17}$ This is Frankfurt's own recurrent usage. See Frankfurt $(200445,57,90)$.
} 
An obvious problem for irrationalism is to differentiate between love and obsession, infatuation, and mere urges holding the man in the grip of the power of attraction to another person (or even an abstract object). From the inside these psychic phenomena may appear sufficiently similar to love. And yet one might wish to refuse dignifying them with the name of love. Frankfurt's preferred response is to stress again the disinterested character of love. The necessary manifestation of love is its disinterested concern. When a lover demands something from the beloved, or when he uses the beloved to pursue his own interest, and when his demand and pursuit become an integral component of what he described as 'love', then we are no longer dealing with a genuine instance of love. This response helps setting apart, for example, cases of sexual obsession so familiar to us from popular culture. In such cases there is a demonstrable self-interested motive driving the putative lover.

The disinterested character of a loving concern prevents the benefactor from complaining about putative ingratitudes, let alone demanding positive rewards. If he is to do so, he would misdescribe his earlier act of beneficence, or worse, confess his earlier insincerity. That lovers are often heard complaining about the lack of response from their beloved is evidence, I think, for the fact that it is difficult to maintain the loving attitude. It is difficult to fully commit oneself to the good of the other for any prolonged period of time. ${ }^{18}$ Irrationalism puts an additonal slant on the same idea. We cannot choose and cannot decide to love a particular person (or object). Love, no less than infatuation, holds us in its grip. Why then is the beneficiary obligated to respond to a particular psychic condition of the benefactor? And even supposing that some response is merited, why is the beneficiary expected to respond in any way distinct from some observer's response?

At a very basic level, then, it is not clear what exactly the beneficiary should convey with his grateful response. It cannot, for example, be a response to the appreciation of his excellent qualities, since the benefactor did not act on the account of those qualities. The loving act of beneficence is entirely a story about the lover. The beloved stands as a passive recipient of donations.

When we look at the accounts of gratitude, ancient and modern, a tension is evident between the idea that the benefactor's motivation is merely to help the beneficiary, and the idea that an obligation to reward the benefactor is simultaneously created. Just look again, if only briefly, at the three influential writers already cited before. Seneca begins by acknowledging the disinterested nature of benevolence:

Suppose someone has done me a favour, and I have accepted it in the way that he wished it to be accepted. He has got what he is after, indeed the one thing he is after. And this means that I have shown gratitude. (On Favours II 33.1) ${ }^{19}$

But then he goes on to add a 'secondary' reward owed in the act of gratitude:

[T] he first reward for doing a favour is in one's consciousness of it (one gets this when the good turn goes where one wanted it to go), while both one's

\footnotetext{
${ }^{18}$ But see the discussion of relationism below.

${ }^{19}$ Seneca translations are from the Seneca (1995) edition.
} 
reputation and the things which might be bestowed in return are a secondary reward. So when a favour has been accepted in a friendly way, its author has already received a repayment in good will, though not, as yet, a material recompense. I still owe him something extra. (On Favours II 33.3)

While modern writers tend to be more circumspect, the tension never goes away. John Simmons builds his theory of gratitude on the distinction between actions done for reasons of self-interest in a cooperative scheme and actions done out of benevolence: only the latter merit gratitude. On the other hand, gratitude is defined as an act of 'requital' of the benefits granted by the benefactor. ${ }^{20}$ The main thrust of Simmons' discussion is to establish the exact circumstances under which this requital would be obligatory. But a question is never asked why it would be obligatory under any circumstances at all-that is, whether benevolence disqualifies the obligation of requital.

Fred Berger is even more cautious. In the passage already quoted earlier he denies that an act of gratitude is a requital:

[Gratitude] does not consist in the requital of benefits but in a response to benevolence; it is a response to a grant of benefits (or the attempt to benefit us) which was motivated by the desire to help us. (Berger 1975, 299)

The terminology of 'response' inherited from Strawson and Hume is as innocuous as it can get. Yet, on the other hand, expressions of gratitude are said to be 'proportionate' to the benefits given (page 301). ${ }^{21}$ Some such expressions (or 'demonstrations', as Berger calls them) are clearly inappropriate: one does not express gratitude to his parents by a handshake and kiss on the cheek (page 303). For an act to be appropriate, it must match the depth and intensity of the attitude it is supposed to express. Thus a handshake, for unproblematic conventional reasons, cannot convey a deep sense of appreciation and concern for the person. However, this criterion of appropriateness becomes relevant only upon granting the following premiss: the recipient of benefits must have an attitude of concern and respect for the benefactor, proportionate to the respect and concern the benefactor has already shown. ${ }^{22}$ As far as one can see, Berger's account provides no justification for it.

Rather than digging up more textual evidence, let me put the problem in an abstract form. Suppose $X$ has done a considerable favour to $Y$, such as saving him from bankruptcy. Suppose he did that out of goodwill and in such a way as to set up a prima facie obligation of gratitude on the part of $Y$ (e.g., by satisfying Simmons' five conditions). ${ }^{23}$ Suppose $Y$, in accepting the gift, did his best to demonstrate to $X$ his

\footnotetext{
${ }^{20}$ See Simmons $(1979,168)$.

${ }^{21}$ Proportionality is commonly understood to be context-sensitive. If a teacher invested time and effort in helping a student to graduate, clearly the student cannot express his putative gratitude by helping the teacher in his studies. For a detailed discussion of fitting and proportional rewards see Beeker (1986, 105-113).

${ }^{22}$ This premiss appears to be made in page 302 .

${ }^{23}$ See Simmons (1979, 178).
} 
gratitude. He praised $X$ in front of other people. He communicated his acknowledgement as competently as one could in his situation. However, years later, when $X$ in turn was on the brink of bankruptcy, $Y$ refused to provide help, although he easily could. As I see it, Berger, no less than Simmons and Seneca, would treat this action as an act of ingratitude, indeed a typical such act. So it should seem that $Y$ 's earlier response was not sufficient. It should seem that, other things being equal, $Y$ is placed under the obligation of gratitude until he reciprocates $X$ 's gift in such a way that his reward would more or less match the material value of the gift.

The problem would never arise, of course, if the interaction between $X$ and $Y$ could be described as an exchange. If there is such an exchange, then fairness demands the requital be proportionate to the benefit. However, to admit the exchange is to assimilate the concept of sui generis gratitude to market gratitude. All three theorists, therefore, should deny that there is an exchange going on. But it is not clear at all how they could substantiate their denial. Their accounts suffer from a conceptual double vision. Upon assuming the disinterestedness of benevolence, they proceed to justify the proportionality of a reward the benevolent act somehow requires. The beneficiary is said to owe a 'debt' to the benefactor, even though the purpose of the beneficent act has been achieved in the very fact of the provision of benefits. The idea of sui generis gratitude thus interpreted is rendered unintelligible.

\section{Alternative Views of Love}

The argument in the previous section has taken the form of a modus ponens: if we interpret love according to irrationalism, then the duty of sui generis gratitude is unintelligible. And since irrationalism was assumed as the most plausible account of love, the statement in the consequent followed. But one might complain that the minor premiss has not been adequately defended. Let us consider some other views of love to see if according to any of them a beneficial act should warrant a grateful response. Our failure would lend more credibility to the conclusion that sui generis gratitude is unintelligible. ${ }^{24}$

Suppose, therefore, we endorse qualitativism: love is a rational response to a set of qualities the lover $X$ attributes to the beloved $Y$. A conjunction $F$ of these lovable qualities gives $X$ a reason to develop love for $Y .{ }^{25}$ Needless to say, each lover may have his own preferred conjunction $F$. This view has come under a sustained attack. One problem is that the person often cannot formulate and name the qualities that he appreciates in his lover. And when he can, these imperfect formulations come after the fact, after his love has already developed. Secondly, there are many instances of loving attitudes that cannot plausibly be interpreted as responses to qualities. Familial love and romantic love often take root, and survive, despite the problematic qualities of the beloved.

\footnotetext{
${ }^{24}$ I insist on nothing stronger than 'more credibility', since, although I discuss the most influential current views, I do not pretend to offer an exhaustive taxonomy of love theories.

${ }^{25}$ As articulated in Taylor (1976).
} 
These worries aside, what relevance does qualitativism have for the analysis of gratitude? One could argue as follows. The benefactor donates because he positively evaluates certain qualities of the beneficiary. And because the beneficiary should appreciate that earlier positive evaluation of himself, he should demonstrate his appreciation in action. To do so is to discharge the duty of gratitude. But we are now moving in circles. If we cannot understand the nature of gratitude, we cannot also understand the duty of 'appreciation'. Why should anyone at all appreciate love (created by a response to qualities), and why it falls exactly on the beneficiary, and not on anyone else, to appreciate that love-all this remains unclear.

If qualitativism does not advance our understanding of gratitude, let us consider yet another account of love. Familial love in particular brings to the fore the centrality of relations ignored by qualitativism. Hence relationism identifies relational properties as an essential set of love's reasons. ${ }^{26} X$ loves $Y$ because he believes that their relationship, rather than $Y$ 's qualities, is worthy of love. The beloved can no longer be replaced. For her to be replaced, we need to reproduce the history of her involvement with $X$. Evidently no-one can have that history except herself. Relationism also seems better suited to take account of familial love. We love our family members, one would wish to say, not for the reasons of their qualities, but for the fact of being related to them. Again, the relevant relation here is not a biological one. It is rather the same historical relationship one builds with one's relatives.

While we may grant relationism its advantages over qualitativism, it might still be an implausible view to hold. We may love someone, but not wish, or not be able, to have a relationship with that person. A father not getting along with his son is estranged from him, yet secretly follows his progress. In his will the father leaves all his considerable fortune to the son. A woman falls in love with a man, but goes on to marry someone else. She keeps his portrait and memorabilia and thinks of him every day to the day of her death, but never sees him again. In all such cases narrated to us by history and literature love is real and intense, but no relationship ever develops. There is of course some historical relation in the sense that the beloved is part of the lover's life. But this is a trivial matter, so far as love is extended in time at all. It is also very clear that no such relation can provide reasons for love. On the contrary: love provides reasons for maintaining secret interest and concern.

Be that as it may, how might a relationist interpret a beneficial act done out of love? What would be the point of such an act? There are two cases to consider: when the benefactor $X$ and the beneficiary $Y$ are not in a loving relationship, and when they are. I will only address the slightly more difficult former case, since the discussion and the objections can be easily paraphrased for the latter one.

Suppose $Y$ receives a benefit from a person $X$ whom he only met a week ago. A relationist cannot very well interpret $X$ 's action as done out of love. For love to exist, there must be a relationship between the lover and the beloved. So $X$ 's action is better seen as an attempt to initiate a loving relationship. It is a form of a proposal to $Y$ to create a relationship. Thus, in accepting the gift, $Y$ consents to begin the relationship.

\footnotetext{
${ }^{26}$ See Kolodny (2003).
} 
An act of gratitude should then be seen in the framework of a budding relationship. ${ }^{27}$ The benefactor's gift is now construed as a step in establishing a loving relationship with the beneficiary. The beneficiary, in accepting the gift, confirms his wish to have such a relationship with the benefactor. If, where the opportunity presents itself, he does not reward the benefactor, he unilaterally violates the relationship.

A major problem with this view is that betraying a loving relationship does not appear at all similar to acting ungratefully. Imagine that Emma, a devoted wife, took exemplary care of Charles. Charles also took care of Emma, but markedly to a lesser degree, being too busy with his job. Imagine that one day, after twenty years of a happy marriage, Emma eloped with Leon. It is right to think that Emma betrayed Charles and their relationship. It is rather strange to think that her elopement represented ingratitude. And vice versa, not every ingratitude is a betrayal of a relationship. Recall our earlier example: $X$ saves $Y$ from bankruptcy, but $Y$ later fails to help $X$ in similar circumstances. It may be that $X$ and $Y$ failed to develop any relationship altogether after $X$ 's action, that they have never interacted again before the ungrateful act of $Y$. Yet $Y$ would still be considered paradigmatically ungrateful. There is no reason to believe that either Seneca, or Berger, or Simmons, would dispute that.

There are, then, doubts of a very basic sort whether sui generis gratitude and ingratitude can be explicated as moves in a loving relationship. That being said, relationism captures well the dynamic of human interaction that is not based on love. I return to this subject shortly in section "Feelings, Reciprocity, and Helping Strangers".

\section{Feelings, Reciprocity, and Helping Strangers}

So far I have argued for the following claims:

1. People are capable of acting on the motive of love.

2. If love is interpreted according to the irrationalist model, a proper moral reaction to it can only occur in the context of goodwill.

3. An emotional reaction to love in the context of goodwill can be described as approval or love.

4. But such a reaction cannot involve a duty of a reward constitutive of sui generis gratitude.

The duty of sui generis gratitude, putatively distinct from fairness, could not be explicated. In contrast to Hobbes, we do not doubt the reality of goodwill: loving actions can and do occur. We should, however, doubt the duty of a special response to such actions.

This argument faces a number of objections. One is that, while its rational justification is elusive, the duty of gratitude could still have a self-evident emotional

\footnotetext{
${ }^{27}$ An abbreviated statement of this idea is found already in Berger (1975: 302). It is elaborated more fully in Card (1988). I ignore another idea of Card's, namely that of thinking of gratitude in accordance with the model of trusteeship. Thinking of the beneficiary as a trustee, rather than a debtor, is supposed to address the fact that the beneficiary might erroneously feel inferior towards the benefactor.
} 
justification. People respond to benevolent actions performed towards them, or even to the attempts of such actions, with a certain kind of emotion. This emotion we label 'gratitude' which is uniquely suitable as a response to goodwill. To say that, logically speaking, gratitude in the context of goodwill is unintelligible is to ignore its psychological reality. To paraphrase a familiar Humean point: a beneficiary is supposed to have a natural emotion of gratitude in reaction to the gift. To lack it is to demonstrate a serious corruption of your moral character. ${ }^{28}$ The reward of gratitude is a manifestation of this emotion, if of nothing else. The emotion of gratitude, apart from being psychologically real, is action-guiding. Placed under its influence, we develop a desire to reward the benefactor-even long after the original act of benevolence. The most that the argument above allows, in the claim 3, is the emotion of approval felt by the beneficiary. But while this emotion fairly characterises the reaction of the observers, it fails to do so with regard to the beneficiary.

Well, I certainly do not wish to deny that putative beneficiaries often experience some kind of emotion. I also agree that the emotional states of a beneficiary on different occasions of receiving a gift, or of different beneficiaries on the occasions of receiving a pro tanto similar gift, may be sufficiently similar for us to talk about the same type of an emotional state. But there is no certainty as to how to interpret this emotion. We could say, for example, that it contains 'affection' and 'warmth' towards the benefactor. These descriptions of the emotion point at its affinity with the emotion of love. It may further be said that the gratitude emotion generates the desire to provide the benefactor with our own gift. That is a typical characteristic of gratitude. Then again, the emotion of love may also be an effective cause for the very same desire. The emotion is real, but there is no sufficient evidence to classify it as a unique emotion of gratitude. The evidence is consistent with classifying it as an emotion of love.

Another and a more serious objection is that not every act of beneficence can plausibly be interpreted as an act of love. Love is a disinterested attitude, but not every disinterested attitude is love. I am writing a reference letter to a student I last saw a few years ago and whom I barely know. I am doing a favour (I may very well decline to write the letter). I benefit that student, and I am not expecting a favour in return. It is appropriate for that student to be grateful, even if mildly so. Do I therefore love that student? This is too absurd: biting the bullet is hardly an option here.

So why do I help the student? Presumably the answer should run along these lines: I think of myself as being in a certain relationship with the student. The fact of this instructor-student relationship, by itself, gives me a reason to help. I help my former student because he is my former student. We are, that is, in a kind of relationship that entails, by its very existence, a reason for the provision of service. Relationships between colleagues, friends, and acquaintances display a similar quality. I help my colleagues because this is what colleagues do. So I help my colleague because he is my colleague. It is wrong to impute a self-interested motive to a colleague who helps. To do so is to reduce collegial relations to business relations. By the same token, if

\footnotetext{
${ }^{28}$ This is the option taken up in Weiss (1985).
} 
I write the letter with the view of getting a benefit from the student later on, then in effect I sell my service. Then I think of myself as being in a business relationship.

Yet it would also be premature to conclude that services to friends and colleagues are literally 'free'. Here we have to notice that reciprocity is an integral element of friendship. Just as I help my friend because of the fact of our friendship, so will he be motivated to help me when circumstances demand. And if he is not so motivated, and if reciprocity is absent, then our friendship will break down. Any social relationship existing between us after reciprocity has repeatedly been violated cannot be interpreted as a relationship between friends. The same should be said of the relationship between colleagues, again construed broadly.

Reciprocal services are constitutive of certain relationships. To be in such a relationship is to be committed to providing services and to expect services to be provided to you. But now, within the context of these relationships, gratitude is strangely out of place. Services to friends and colleagues, students and instructors, should be reciprocated-but not out of gratitude. They should be reciprocated simply because maintaining these relationships requires uninterrupted flow of services in both directions. ${ }^{29}$

Even if this appeal to reciprocity is to be granted, the objector might still press on with a case of helping utter strangers. Sometimes we are prepared to help people with whom we cannot sensibly be said to be in any social relationship and with whom, moreover, we do not purport to establish any such relationship. Anonymously donating money to charity, helping people on the street-all these familiar beneficial acts cannot be interpreted as moves in a relationship. As we saw already in the bankruptcy example in section "Alternative Views of Love", the scope of beneficence and gratitude extends beyond the practice of relationships.

Anonymous beneficence in particular, where the benefactor and the beneficiary are unaware of each other's identity, has this troubling feature that the benefactor does not, even cannot, intend to benefit that beneficiary. Why then are we imposing obligation on the beneficiary, and no one else, to show gratitude to the benefactor, when the latter's identity is subsequently revealed? It is not difficult to understand the sociological and economic factors encouraging this practice of gratitude. ${ }^{30}$ What is missing is a normative justification. The objector, however, may resist the demand of exactly such justification and declare gratitude an irreducible fundamental duty. And if in the case of helping strangers we are unable to defend a fitting response to the benefactor on any other grounds, perhaps the objection should stand. Observe, on the other hand, that this will not represent any major concession on our part. Gratitude is commonly thought to pervade our lives. But we have only been able to recognise it, tentatively, in a rather narrow class of cases of helping strangers.

A more ambitious reply to the objector will not tolerate even this concession. I am only able to sketch it here in a briefest outline. Help to strangers and gratitude to

\footnotetext{
${ }^{29}$ Of course, the usual caveats apply with regard to the appropriateness of particular service offerings and responses thereof. See footnote 21 .

${ }^{30}$ See, e.g., (Gouldner 1973c, 244-251) and (Gouldner 1973b, 269-271).
} 
strangers should be explained by the same notion of reciprocity. We begin with the following assumption:

Simmels thesis Any interaction between individuals creates a relationship between them, and any relationship is underwritten by reciprocity. ${ }^{31}$

By 'interaction' is understood a transfer of an asset, not necessarily requested explicitly, but such that would have been requested had the person's interests been taken into account under the conditions of minimal reflection. ${ }^{32}$ Obviously 'assets' are understood abstractly enough, so that praise, for instance, will also qualify as such. Further casuistry is needed to deal with such questions as whether a request for interaction - say, a cry for help-is itself a transaction, or the question how to interpret theft that, after all, also involves a physical movement of an asset. ${ }^{33}$ This should be relevant for taking the notion of interaction further afield.

Limited as we are by the subject of gratitude, we need not worry about these complications. More urgent is the need to understand the nature of the relationship initiated by the interaction (to repeat, where an asset has moved from the benefactor to the beneficiary). Suppose that such a relationship belongs to the class of reciprocal relationships explicated earlier. Then what exactly is the content of saying that before the interaction the two parties were not in a reciprocal relationship and that after it they were? My suggestion is as follows: for the benefactor $X$ to enter into a reciprocal relationship with the beneficiary $Y$ is to effect a change in the overall set of reasons that $Y$ has in the performance of his actions toward $X$. This is a very general metaphysical explication. It has, however, concrete practical consequences. In accepting help and thus entering into a reciprocal relationship with the benefactor, the beneficiary is bound by reciprocity in his subsequent dealings with that benefactor. According to this explanation, therefore, what we see as a duty of gratitude turns out to be, once again, a move in a reciprocal relationship.

Now, why should there be an obligation to obey the terms of a reciprocal relationship? As I see it, the simple answer is that the principle of reciprocity-that every asset transfer must receive a fitting response-is common knowledge. Any provision of any service, as is its acceptance, is done on the assumption that reciprocal mechanisms are in play. A failure to reciprocate, upon the acceptance of the service, would be nothing other than cheating. This basic fact being known to every mature agent, the unresolved question is what exactly should count as a fitting response to the given service. The latter issue is the usual source of frustration and conflict. ${ }^{34}$

\footnotetext{
${ }^{31}$ See, e.g., Simmel (1990:82-83). Simmel's original term for interaction is 'Wechselwirkung'.

${ }^{32}$ By 'minimal reflection' I understand responsiveness to reasons. See Raz (2000:19-20) for this notion. The concept of interaction should be kept distinct from the concept of business transaction (more on this below). Simmel intended 'interaction' to cover an extraordinarily broad range of activities. Thus he says, e.g., that every glance at another person, not just a menacing stare or a happy face, would be a form of interaction where 'personal energy' and 'personal substance' is transferred. This entails metaphysical commitments that I am not prepared to make at the moment. My formulation implies transfer of more familiar assets.

${ }^{33}$ Cry for help: see footnote 32. Theft and negative reciprocities: Sahlins (1972:195) and Davis (1992:24).

${ }^{34}$ On this account, an act of love should also be reciprocated. But the fitting response comes down to as little as the very acceptance of the service. See the Seneca quotation above.
} 
If this, however, is our explanation, then it is open to the further charge that it blurs the distinction between the context of market and the context of reciprocal relations. In both contexts provision of benefits is interpreted as a move in a mutual exchange. The benefactor $X$ interprets the acceptance of the benefit as a sign of expecting a possible further reward from the beneficiary $Y$-in the framework of the newly built, or ongoing, relationship. What should $Y$ 's proper response be, according to this view? The beneficiary, in understanding the intentions of $X$, must understand that the acceptance of the benefit comes with a price: he commits himself (or reaffirms his commitment) to some kind of a relationship. He is expected to reciprocate $X$ 's good deed in the course of that relationship. Observe as well that in both contexts ingratitude is explicated as a violation of the terms of exchange. So understood, this exchange of services is not different from a business exchange. This is implausible, so far as relationships between friends and colleagues are thought to be different from market relations.

One might of course try to argue, together with Hobbes, that the difference is illusory, and that at bottom all our relations are equally self-interested. But this avenue is already closed to us. A more promising response to the charge is to say that in non-market relationships, reciprocity and the requirement to protect the benefactor's self-interest feature as mere conditions sine qua non. They are conditions merely necessary for the performance of service. ${ }^{35}$ When the instructor writes a reference letter, he is let to understand that the student will not harm him in return. But this understanding is not part of his motivation. What motivates him is the desire to help the student. Or so we are told.

We are supposedly familiar with this distinction everywhere in our actions. You are starting a car. Had you known there is no petrol left in the tank, you would not have bothered. Yet, in your attempt to start the car, you are not motivated by the presence of the petrol. Is this so clear though? Your goal in starting the car is, let us say, to get to a theatre. Driving the car is a way of getting to the theatre, and starting the car is the way of beginning to drive. Assuming you know that the engine of your car runs on petrol, it is not as though you simply intend to turn the ignition. Rather you intend to turn the ignition in a car equipped with the engine, inflated tyres, loaded battery, and petrol in the tank. You turn the ignition in part because you believe that there is petrol in the tank. So this belief plays a small, but recognisable, role in motivating you to turn the ignition. But will it also explain why you came to the theatre? This is a supposition too absurd to contemplate. What is not absurd, however, is the following: the belief that there is petrol in the tank motivates you to choose a particular way of getting to the theatre. Absent that belief, you would have walked.

The alleged mere necessary condition now turned out to have a role in motivating you to take a particular means towards the end. The end itself, however, need not at all be conducive to your self-interest. Analogously, then, the instructor's end is to help the student. But any way of helping the student ought to involve a transfer of an asset (reference letter, the instructor's time etc.). Thus it constitutes an interaction with that student. According to Simmel's thesis, any such interaction is governed by

\footnotetext{
${ }^{35}$ For a useful discussion of sine qua non conditions see Hart and Honoré (1985).
} 
reciprocity. That is, we engage in interactions with other people in the belief that our actions will be appropriately reciprocated.

In the context of market the situation is reversed. Provision of services is done there with the goal of securing the interest of the 'benefactor'. The interest of the other party is a mere means towards this goal. Another interesting contrast, logically connected to the one just mentioned, is that the identity of the beneficiary is essential to the service provision in the context of reciprocal relationships. For example, my motive in writing the letter for a student $S$ is to help that very $S$. I do not write a letter with the goal of helping some student, while $S$ simply happens to be the one around. In a market exchange the identity of the beneficiary is incidental. A shop owner does not care whether this particular customer buys his stock. He is simply selling his products - to any customer who is ready to pay. But a further elaboration of this issue should await another occasion.

Acknowledgments I am grateful to Yasemin Topac and Roslyn Weiss for helpful comments on the earlier versions of this paper.

\section{References}

Bargiela-Chiappini, F. (2003). Face and politeness: new (insights) for old (concepts). Journal of Pragmatics, 35(10-11), 1453-1469.

Becker, L.C. (1986). Reciprocity. Routledge \& Kegan Paul.

Berger, F.R. (1975). Gratitude. Ethics, 85, 198-209.

Buck, R. (2004). Gratitude and subjective well-being. In R.A. Emmons \& M.E. McCullough (Eds.), The Psychology of Gratitude: Oxford University Press.

Card, C. (1988). Gratitude and obligation. American Philosophical Quarterly, 25, 115-127.

Davis, J. (1992). Exchange. University of Minnesota Press.

Elias, N. (1982). The Civilizing Process, Vol. 1. Pantheon Books.

Fitzgerald, P. (1998). Gratitude and justice. Ethics, 109, 119-153.

Frankfurt, H.G. (2004). The Reasons of Love. Princeton University Press.

Gilbert, M. (2006). A Theory of Political Obligation. Oxford University Press.

Gouldner, A.W. (1973a). For Sociology. Allen Lane.

Gouldner, A.W. (1973b). The importance of something for nothing. In Gouldner (1973a).

Gouldner, A.W. (1973c). The norm of reciprocity. In Gouldner (1973a).

Hart, H.L.A., \& Honoré, A.M. (1985). Causation in the Law, 2nd edn. Oxford University Press.

Herman, B. (1993). The Practice of Moral Judgment. Harvard University Press.

Kant, I. (1991). The Metaphysics of Morals. Cambridge University Press. Translated by M. J. Gregor.

Kasper, G. (1990). Linguistic politeness: Current research issues. Journal of Pragmatics, 14(2), 193-218.

Kolodny, N. (2003). Love as valuing a relationship. Philosophical Review, 112(2), 135-89.

Raz, J. (2000). Engaging Reason. Oxford University Press.

Sahlins, M.D. (1972). Stone Age Economics. Aldine-Atherton.

Seneca, L.A. (1995). Moral and Political Essays. Cambridge: Cambridge University Press.

Simmel, G. (1990). The Philosophy of Money. Routledge, second enlarged edition. Edited by D. Frisby.

Simmons, A.J. (1979). Moral Principles and Political Obligations. Princeton University Press.

Smit, H., \& Timmons, M. (2011). The moral significance of gratitude in Kant's ethics. The Southern Journal of Philosophy, 49, 295-320.

Taylor, G. (1976). Love. Proceedings of the Aristotelian Society, 76, 147-64.

von Tevenar, G. (2006). Gratitude, reciprocity, and need. American Philosophical Quarterly, 43(2), 181188.

Walker, A.D.M. (1980). Gratefulness and gratitude. Proceedings of the Aristotelian Society, 81, 39-55.

Weiss, R. (1985). The moral and social dimensions of gratitude. The Southern Journal of Philosophy, 23, 491-501. 